\title{
Spatial analysis of North Sea cod recruitment: concurrent effects of changes in spawning stock biomass, temperature and herring abundance
}

\author{
Dag Ø. Hjermann ${ }^{1, *}$, Jonathan A. D. Fisher ${ }^{2}$, Tristan Rouyer ${ }^{1}$, Kenneth T. Frank ${ }^{3}$, \\ Nils C. Stenseth ${ }^{1,4}$ \\ ${ }^{1}$ Centre for Ecological and Evolutionary Synthesis (CEES), Department of Biology, University of Oslo, PO Box 1066 Blindern, \\ 0316 Oslo, Norway \\ ${ }^{2}$ Centre for Fisheries Ecosystems Research, Fisheries and Marine Institute of Memorial University of Newfoundland, \\ PO Box 4920 St. John's, Newfoundland A1C 5R3, Canada \\ ${ }^{3}$ Fisheries \& Oceans Canada, Bedford Institute of Oceanography, Ocean Sciences Division, Dartmouth, Nova Scotia B2Y 4A2, \\ Canada \\ ${ }^{4}$ Institute of Marine Research, Department of Coastal Zone Studies, Flødevigen Research Station, 4817 His, Norway
}

\begin{abstract}
The decline of the North Sea cod Gadus morhua has been attributed to both overfishing and ocean warming. However, another hypothesis is that overfishing of piscivorous cod has caused an increased abundance of formerly predatory-controlled pelagic fish including herring Clupea harengus, which in turn has suppressed the recruitment of cod through predation on the early life stages of cod. Here we analyze $40 \mathrm{yr}$ of trawl survey data in order to explore how the abundance of young herring affects cod recruitment, and how cod biomass affects the abundance of herring. In both cases we also take into account the effects of spawner biomass (of cod and herring, respectively) and sea temperature. We take a novel, explicitly spatial, approach by analyzing these effects on a local $(185 \times 167 \mathrm{~km})$ scale. Our results indicate large spatial variability in ecological mechanisms. In the German Bight, high cod recruitment is associated with low herring abundance, low temperatures and high overall cod spawner biomass. This area used to contain a large portion of the cod recruits, and there is a strong correlation between the fraction of cod recruits found in this area and overall recruitment. In this area, herring recruitment is also negatively associated with the abundance of large cod. Thus, for this part of the North Sea, our findings are consistent with a reversal of dominance between cod and herring; however, herring may affect the cod by competition rather than by predation.
\end{abstract}

KEY WORDS: Interspecific interaction · Ecosystem dynamics $\cdot$ Cultivation effect $\cdot$ Predator-prey reversal $\cdot$ Spatial heterogeneity $\cdot$ Warming

\section{INTRODUCTION}

The complex interplay between the species in an ecosystem creates the potential for complex behaviour, including multiple stable states (May 1977). One typical mechanism for such a situation is that per-capita recruitment declines when the population becomes small, known as the demographic Allee effect (Courchamp et al. 2008). As large adults, predatory fish like cod Gadus morhua eat small pelagic fish like herring Clupea harengus, but in turn, pelagic fish may also prey upon and compete with the smaller, early life stages of their predators. A high biomass of adult predators keeps down species that may be predators/competitors of its eggs and larvae in size-structured ecosystems; this has been termed the 'cultivation effect' (Swain \& Sinclair 2000, Walters \& Kitchell 2001). When harvesting reduces the abundance of predators, natural mortality of its young life stages may increase, leading to a feedback 
loop that may hamper or delay recovery of fish stocks after overfishing (de Roos et al. 2003, Frank et al. 2011, Richardson et al. 2011).

While ecosystem models often disregard space, ocean ecosystems are spatially heterogeneous, both because of spatially varying conditions (depth, temperature, bottom habitat, etc.) and because of the movements of organisms (e.g. fish typically have particular spawning, nursery and feeding areas). Therefore, we expect that the interactions among species change spatially. The most obvious case is that predators and prey will only interact when and where they overlap, but other spatially varying factors may also affect predator-prey overlap: the availability of alternative prey, competition among predators, and the size of predators and prey during the season when they overlap. The North Sea (NS) is an example of a spatially heterogeneous ocean, with spatially varying bottom depths, temperatures and fish communities. Overall, the abundance of cod, both spawners and recruits, has declined steadily in the NS since the 1960s. Two reasons for this decline are commonly regarded as plausible (Fig. 1). First, overfishing has depleted the adult (spawning) stock of cod (Cook et al. 1997, Horwood et al. 2006). Secondly, the NS has warmed substantially in recent decades, and high temperatures are associated with low recruitment of NS cod (e.g. Planque \& Frédou 1999, Olsen et al. 2011). One mechanism for the negative effect of tem-

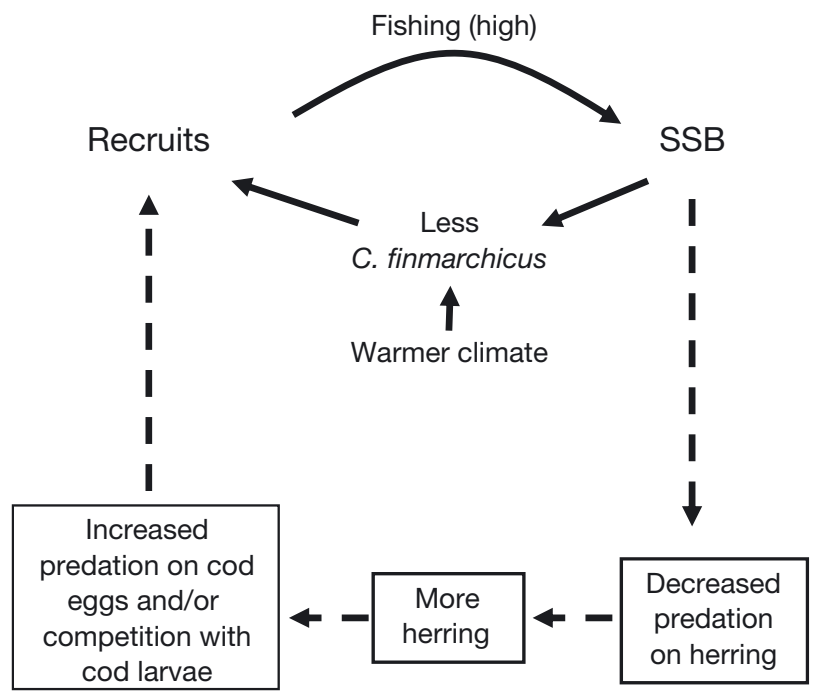

Fig. 1. Proposed mechanisms for the decline of North Sea cod Gadus morhua since the 1960s. Relatively direct mechanisms (solid lines) include the negative effect of high fishing mortality on the spawning stock biomass (SSB) and the negative effect of a warmer climate, via a decrease in the young cod's key prey Calanus finmarchicus, on recruitment. A more indirect mechanism involves the interactions between cod and herring Clupea harengus (dashed lines) perature could be the associated change in species composition and seasonality of zooplankton, which may have led to decreased survival of cod larvae (Beaugrand et al. 2003, Durant et al. 2005, Olsen et al. 2011). The 2 hypotheses of NS cod decline-overfishing and increased temperatures - are not mutually exclusive (Fig. 1; Durant et al. 2005, Olsen et al. 2011); on the contrary, there is some evidence that they may even exacerbate each other's effects (Brander 2005, Kirby et al. 2009). The possible generality of such synergistic effects has been scrutinized by Ottersen et al. (2013, this volume). A third mechanism may be that herring play a crucial role in limiting the recruitment of cod, through predation on, or competition with, cod eggs and larvae (Minto \& Worm 2012). The predation mechanism has been discussed since the 1970s, as a period of exceptionally high recruitment years of cod and other gadoids (the 'gadoid outburst'), which started at approximately the same time that the stock of NS herring began to decline (Cushing 1980). Recently, both Fauchald (2010) and Speirs et al. (2010) have argued in favour of this mechanism. Furthermore, the former author suggested that intensive harvesting of cod has released herring from predator control, the result being a positive feedback loop resulting in hysteresis (Scheffer et al. 2001, Beisner et al. 2003), but that the continued harvesting of herring might prevent the system from changing completely into a pelagic-fishdominated state.

Ecosystem changes following strong reductions in predatory fish have been suggested for other marine areas. In the Baltic Sea, Köster \& Möllmann (2000) found, from stomach samples, that herring and sprat Sprattus sprattus eat large amounts of cod eggs. In the Baltic, there is a large temporal overlap between cod spawning and herring and sprat feeding, and cod eggs are found concentrated in a narrow depth range. Sprat dominated total consumption, but mostly due to their much larger biomass (the per-capita consumption of herring is about one-third lower than that of sprat). Another cascading effect of predatorprey control may also be in action in the Baltic: as cod has decreased, sprat numbers have increased as a result of lower predation pressure, which has contributed to a reduced abundance of Pseudocalanus acuspes, a key prey for larval cod (Möllmann et al. 2008). Additionally, on the eastern Scotian shelf, a former cod-dominated ecosystem, overfishing of cod and other benthic fishes triggered a trophic cascade by releasing zooplanktivorous fish from predatory control, leading to a system characterized by a large abundance of pelagic fish and macroinvertebrates 
(including crabs and shrimp) and poor productivity of cod and other benthic fishes (Frank et al. 2005). However, recently, the ecosystem appears to be returning to a benthic fish-dominated state (Frank et al. 2011). The Black Sea is another case in which the removal of predatory fish has been suggested to cause large system changes; analyses by Llope et al. (2011) suggested that the overfishing of predatory fish eventually pushed the food chain into an alternative state with a large abundance of ctenophores and a low abundance of zooplankton. In both the Baltic and Black Seas, however, substantial changes in environmental conditions, including water temperature, salinity and phosphorous levels have also had significant effects on the system, interacting with trophodynamic factors (Möllmann et al. 2008, Llope et al. 2011); only in the case of the eastern Scotian shelf does the effect of environmental changes appear to have been relatively small (Frank et al. 2011).

In this paper, we analyzed the concurrent effects of stock size, temperature and herring abundance on cod recruitment on smaller spatial scales (rectangles of approximately $185 \times 167 \mathrm{~km}$ ) than have been considered in previous analyses. NS cod is a spatially structured population (Wright et al. 2006, Heath et al. 2008), making it paramount to take into account the spatial aspects of ecosystem processes (Ciannelli et al. 2013, this volume). Also, in order to investigate whether hysteresis is at play, we explored factors that may affect local herring recruitment, including the possible top-down effect of cod on herring. With this approach, we were better able to pinpoint how environmental and trophodynamic effects vary throughout the NS ecosystem, which may be an important step towards a more complete understanding of the ecosystem. Migration of adults and drift of eggs and larvae were not explicitly incorporated in the analyses, as these patterns may vary substantially between years (e.g. Bartsch et al. 1989); however, the results are interpreted in light of existing knowledge of these patterns.

\section{MATERIALS AND METHODS}

\section{Database}

The basis for our analysis were data on fish abundance from the International Bottom Trawl Survey (IBTS), Quarter 1 (i.e. January to March), downloaded from http://datras.ices.dk. We used data for each haul but analyzed them using the IBTS grid, which consists of rectangles of $1^{\circ}$ longitude (53 to $70 \mathrm{~km}$, increasing towards the south) by $0.5^{\circ}$ latitude $(56 \mathrm{~km})$, hereafter denoted 'grid cells' (ICES 2010) across the North Sea (mean grid cell area: $3435 \mathrm{~km}^{2}$, total grid cell area: $663000 \mathrm{~km}^{2}$ ). We used data from 1971 to 2010, as age determination of sampled cod started in 1971. The IBTS started out as a young herring survey using herring gear, but gradually changed to using more multipurpose gear (ICES 2010). Standard gear has been used since 1984, while 10 additional gear types were used before this time. Data from the 6 least common gear types were ignored. For the other 4 non-standard gears, we calculated the catch ratio between hauls of non-standard and standard gear in the same year located $<200 \mathrm{~km}$ apart, and applied linear regression to $\log$ (catch ratio) as a function of distance (in $\mathrm{km}$ ) and number of days between hauls. In the cases where the intercept of these regressions tended to systematically be $<1$ or $>1$, we used the intercept estimates to adjust fish abundance (for details, see Supplement 1 at www. int-res.com/articles/suppl/m480p263_supp.pdf). The data were tabulated both by age and length. The biomass of mature fish was calculated as the fish abundance $\times$ mean fraction mature $\times$ mean weight for each age, summed over all ages (data on maturity and weight are from ICES 2011a,b). Sea surface temperature (SST) was retrieved from the COADS database with $1^{\circ} \times 1^{\circ}$ spatial resolution and monthly temporal resolution (NOAA 2011). From these data we used the mean spring temperature (March to May, i.e. egg and larval stages of cod; Heath et al. 2008) using linear interpolation to quantify the temperature of the centre of each grid cell.

\section{Spatially resolved regression analyses}

We made 2 sets of analyses of abundance variations on a local scale, which we defined to be areas of $3 \times 3$ IBTS grid cells, hereafter denoted 'subareas' (mean size: $185 \times 167 \mathrm{~km}$ ): (1) variations in local cod recruitment as a function of the biomass of cod spawners, SST and the abundance of young herring and (2) variations in local herring recruitment as a function of the biomass of herring spawners, SST and the abundance of large cod. We analysed subareas centred on every grid cell in the dataset (subareas were thus overlapping). When parts of the $3 \times 3$ grid were on land or outside the study area, these parts were simply disregarded. We used only subareas with at least 4 grid cells of data, and where at least 15 yr of data were available. 


\section{Analyses of local cod recruitment}

For every subarea a we performed 3 regression analyses with the subarea's median cod recruitment (Age 1 cod: CodAge1) as the response variable. In the first analyses, we let the predictor variables be the biomass of cod spawners (cod $>50 \mathrm{~cm}$ : CodMature), SST and the abundance of herring that could be predators of cod eggs and larvae or competitors of cod juveniles. For herring as a predator on cod eggs, the literature is equivocal on which size or age group of the herring eats the most cod eggs. Last (1989) found the predation of herring to generally peak in the 15 to $19 \mathrm{~cm}$ interval in spring, largely corresponding to Age 1 herring. As this also is the age group that would be expected to compete most with the cod larvae and juveniles later in the season (they both feed on small zooplankton), we chose the abundance of Age 1 herring in the cod's spawning year as a potential explanatory variable. We used the mean over the subarea for all predictor variables, and all abundance variables were log-transformed.

Cod recruitment was modelled using generalized additive models (GAM). This is a kind of regression model similar to multiple linear regression, except that it allows the effects of each explanatory variable on the response variable to be either linear or non-linear (Wood 2011). We used the mgcv library of $R$, which utilizes the generalized cross validation (GCV) criterion to decide whether each effect is linear or not and, in the latter case, the smoothness of the non-linear effect.

In the first analysis, we assumed that recruitment (the number of Age $1 \mathrm{cod}$ in a given year) was dependent on the local biomass of cod spawners, the temperature and herring abundance in the cod's spawning year (i.e. in the year before):

$$
\begin{aligned}
{\text { CodAge } 1_{a, t+1}} & =\mathrm{s}\left(\text { CodMature }_{a, t}\right)+\mathrm{s}\left(\operatorname{SST}_{a, t}\right) \\
& +\mathrm{s}\left(\operatorname{HerrAge}_{a, t}\right)+\varepsilon_{a, t}
\end{aligned}
$$

where $a$ is a single subarea and $t$ denotes years (all years with available data), HerrAge1 is the abundance of Age 1 herring, and $\varepsilon$ is a normally distributed error term (as mentioned, abundance data were log-transformed). ' $\mathrm{s}(X)^{\prime}$ ' denotes a non-linear spline function of $X$, or a linear function of $X$, in which case $\mathrm{s}(X)=$ slope $\times X$. To avoid overfitting we constrained each spline function to have a maximum of 2 degrees of freedom (i.e. $k=3$; Wood 2011). The second regression analysis was similar, except that we replaced the local biomass of cod spawners (CodMature $_{a, t}$ ) with the biomass of cod spawners in the entire NS (CodMatureTot $\left.{ }_{t}\right)$ :

$$
\begin{aligned}
{\text { CodAge } 1_{a, t+1}=} & \mathrm{s}\left(\text { CodMatureTot }_{t}\right)+\mathrm{s}\left(S S T_{a, t}\right)+ \\
& \mathrm{s}\left(\text { HerrAge }_{a, t}\right)+\varepsilon_{a, t}
\end{aligned}
$$

The motivation for this is that cod eggs and larvae drift for a period, so recruitment does not depend on biomass of spawners in a larger area, while we still expected the effect of temperature and predation from herring to be local. In the third regression analysis, we wanted to specifically analyse shortterm variation. This analysis was similar to the second one, except that all variables were detrended to remove the effect of long-term trends in the data series:

$$
\begin{gathered}
\text { CodAge1D } D_{a, t+1}=\mathrm{s}\left(\text { CodMatureTotD }_{t}\right)+ \\
\mathrm{s}\left(\operatorname{SSTD}_{a, t}\right)+\mathrm{s}\left(\text { HerrAgeD }_{a, t}\right)+\varepsilon_{a, t}
\end{gathered}
$$

where the $D$ at the end of the variable names indicates that the variable was detrended, i.e. replaced with the residual after a linear regression between the original variable and year. Detecting effects in the short-term variation would also constitute quite strong evidence, but as detrending removes much of the variation in both predictor and response variables, the power of the analysis decreases substantially (i.e. it is more likely that p-values are $>0.05$ even though there is a real causal relationship).

In all 3 cases, we performed a model selection procedure independently for each subarea, choosing the model (i.e. the subset of the 3 explanatory variables) with the lowest corrected Akaike's information criterion $\left(\mathrm{AIC}_{\mathrm{c}}\right)$ that also showed $\mathrm{p} \leq 0.05$ for all variables.

\section{Analyses of local herring recruitment}

The analyses of herring recruitment were almost a mirror image of the analyses of cod recruitment: in Eqs. (1) to (3) we replaced cod recruitment and spawning stock biomass (SSB) with herring recruitment (abundance of Age 1 herring: HerrAge1) and biomass of mature herring (HerrMature), respectively. While we expected cod recruitment to be affected by young herring, we expected the abundance of young herring to be influenced mostly by the abundance of large, piscivorous cod, i.e. mature cod. We ran 3 regression analyses equivalent to the analyses of cod recruitment: local effects of all variables, local effects of temperature and predators but effects of total spawner abundance, and analysis of detrended variables: 


$$
\begin{array}{rl}
{\text { HerrAge } 1_{a, t+1}} & \mathrm{~s}\left(\text { HerrMature }_{a, t}\right)+\mathrm{s}\left(\operatorname{SST}_{a, t}\right) \\
& +\mathrm{s}\left(\text { CodMature }_{a, t}\right)+\varepsilon_{a, t}
\end{array}
$$

$$
\begin{aligned}
& \text { HerrAge }_{a, t+1}=a+\mathrm{s}\left(\text { HerrMatureTot }_{t}\right) \\
& +\mathrm{s}\left(S_{S} T_{a, t}\right)+\mathrm{s}\left(\text { CodMature }_{a, t}\right)+\varepsilon_{a, t}
\end{aligned}
$$

HerrAge $1 D_{a, t+1}=\mathrm{s}\left(\right.$ HerrMatureTot $\left.D_{t}\right)$ $+\mathrm{s}\left(\operatorname{SSTD}_{a, t}\right)+\mathrm{s}\left(\right.$ CodMature $\left._{a, t}\right)+\varepsilon_{a, t}$

Again, all abundance variables were log-transformed prior to analysis, and the effect of each variable in each subarea was calculated as explained in the cod recruitment section.

\section{RESULTS}

The biomass of mature cod Gadus morhua decreased greatly in the entire NS during the period from 1971 to 2009 (Fig. 2a), with the exception of the north-easterly areas close to the Norwegian Trench and in the English Channel (Fig. 2f). The decrease was, however, somewhat less in the Central North Sea (northwards from the Dogger Bank) and close to Denmark (Fig. 2f). The recruitment of cod in the southern NS has also decreased substantially (Fig. 2b), and the decrease was strongest close to the Danish, German and Dutch coasts (Fig. 2g). A relatively small part of the NS, the German Bight area, contained around $80 \%$ of the Age 1 cod in some years of the survey, but, since 1993 , has usually contained $<5 \%$ of them (Fig. 3). The fraction of Age 1 cod that was found within this area was strongly correlated with the recruitment of $\operatorname{cod}\left(\mathrm{R}^{2}=0.48, t=5.84, \mathrm{p}<0.0001\right.$; Fig. 3$)$. This relationship remained significant $(t=2.68, \mathrm{p}=$ 0.011 ) if the general decrease in both variables over time was taken into account by using year as a covariate. In contrast, the biomass of mature herring Clupea harengus has generally increased since 1980,

Fig. 2. Gadus morhua and Clupea harengus. Time series and spatial variation in fish abundances from $(\mathrm{a}-\mathrm{d}, \mathrm{f}-\mathrm{i})$ trawl surveys and $(e, j)$ sea surface temperature (SST). (a-e) Abundance (as log-transformed numbers of fish per hour trawling) in the northern (blue lines) and southern (red lines) North Sea, using $55^{\circ} \mathrm{N}$ as the dividing line. The Skagerrak/ Kattegat area (east of $8^{\circ} \mathrm{E}$ ) was excluded. (f-j) Spatial patterns of the relative linear time trends of the variables (the abundance variables were log-transformed). Shades of blue indicate a significant $(p<0.05)$ decrease over time; shades of orange indicate a significant increase. Slopes were estimated for subareas $\left(3^{\circ} \times 3^{\circ}\right.$ grid cell areas). The statistical significance of the time trend is shown by the colour of the central grid cell-dark shading (dark orange or dark blue): $\mathrm{p}<0.001$; medium shading: $0.001<\mathrm{p}<0.01$; light shading: $0.01<\mathrm{p}<0.05$

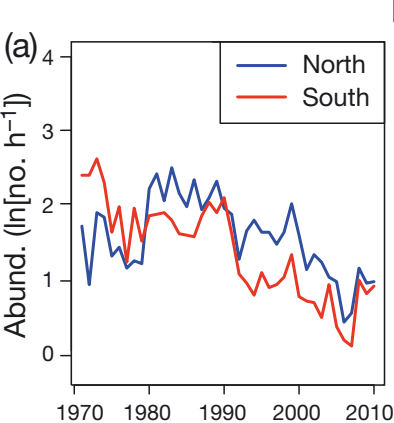

Mature cod
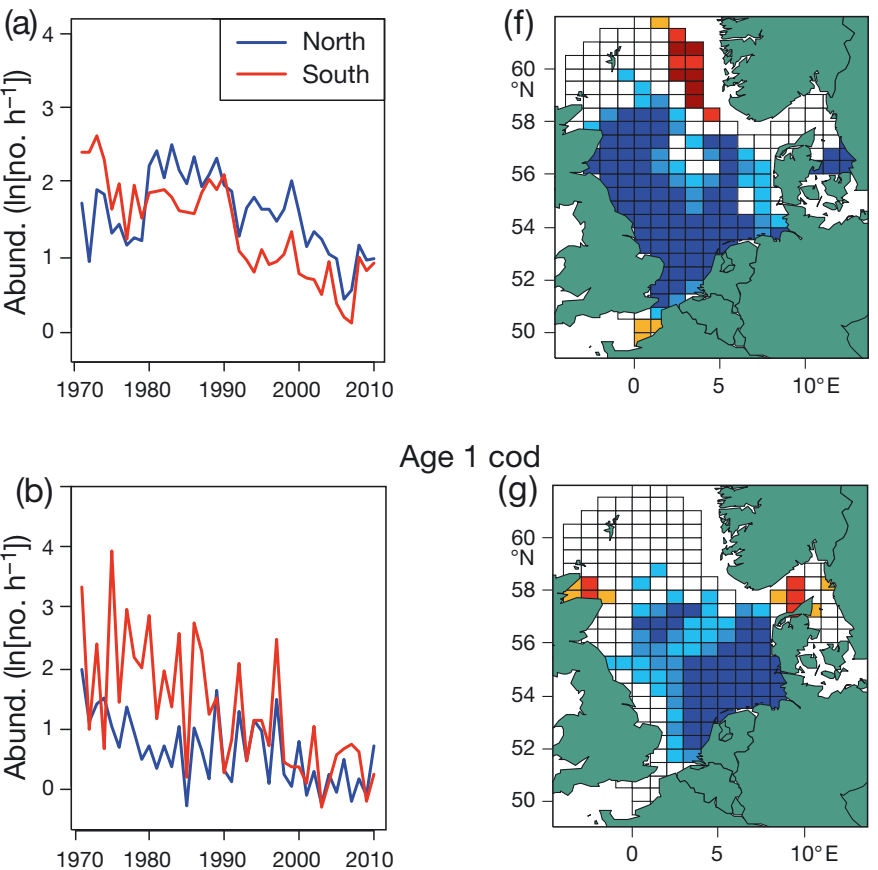

Age $1 \mathrm{cod}$
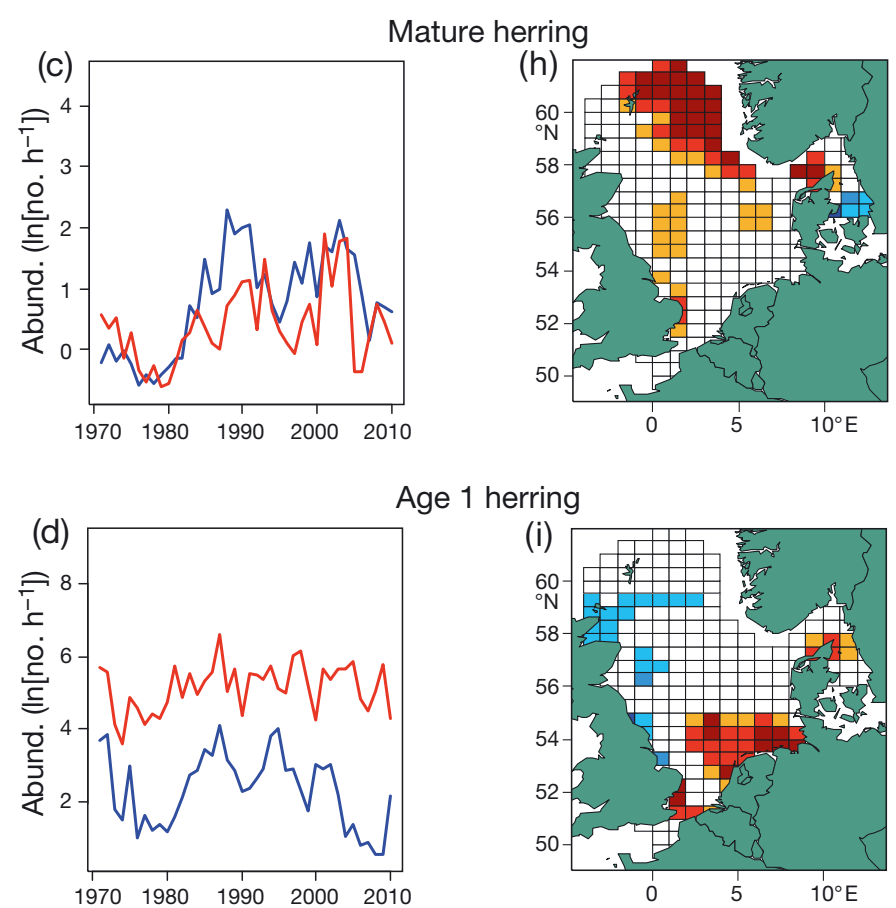

Age 1 herring
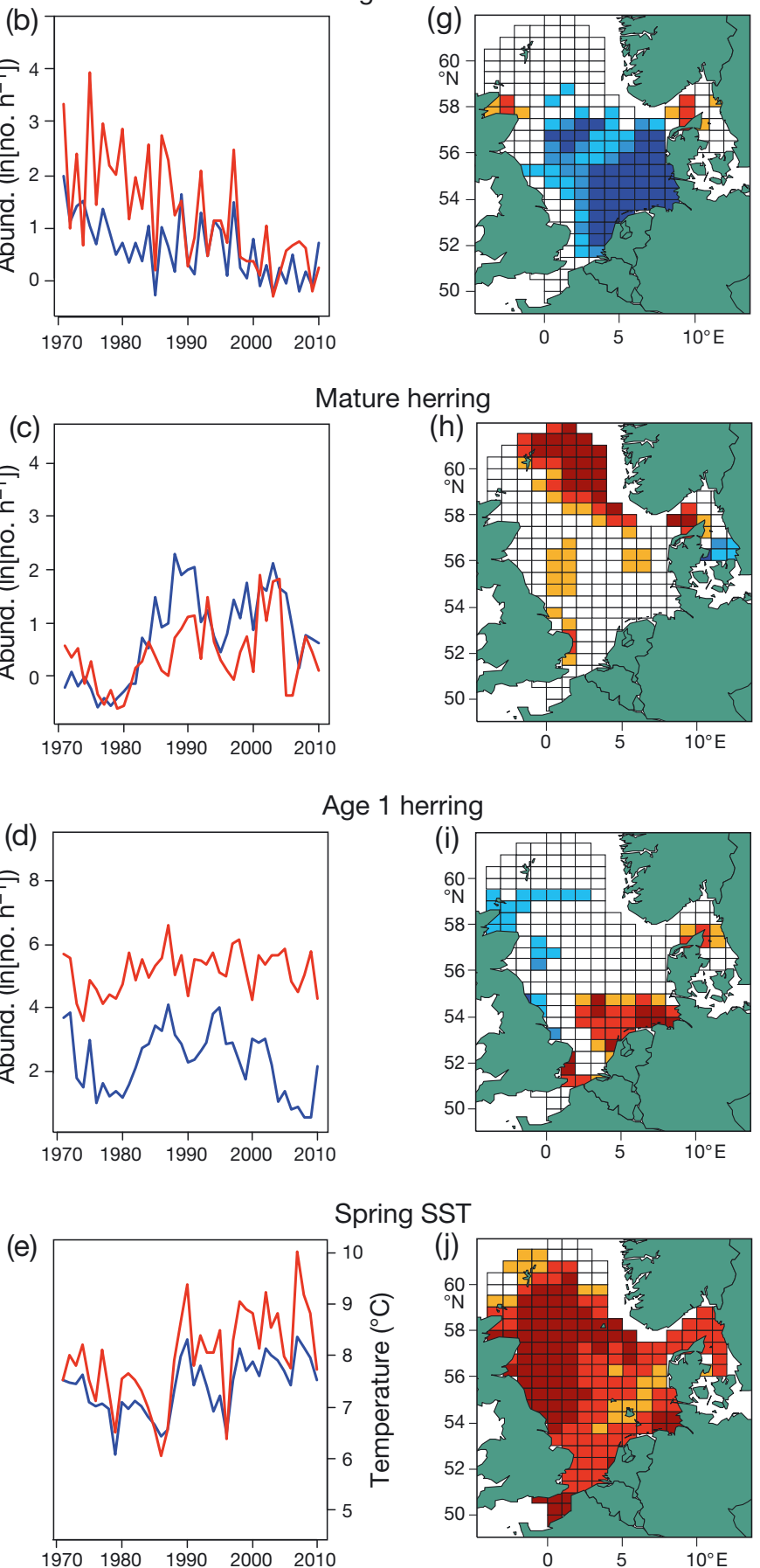

Spring SST

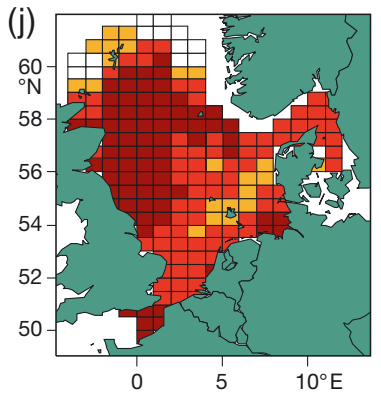




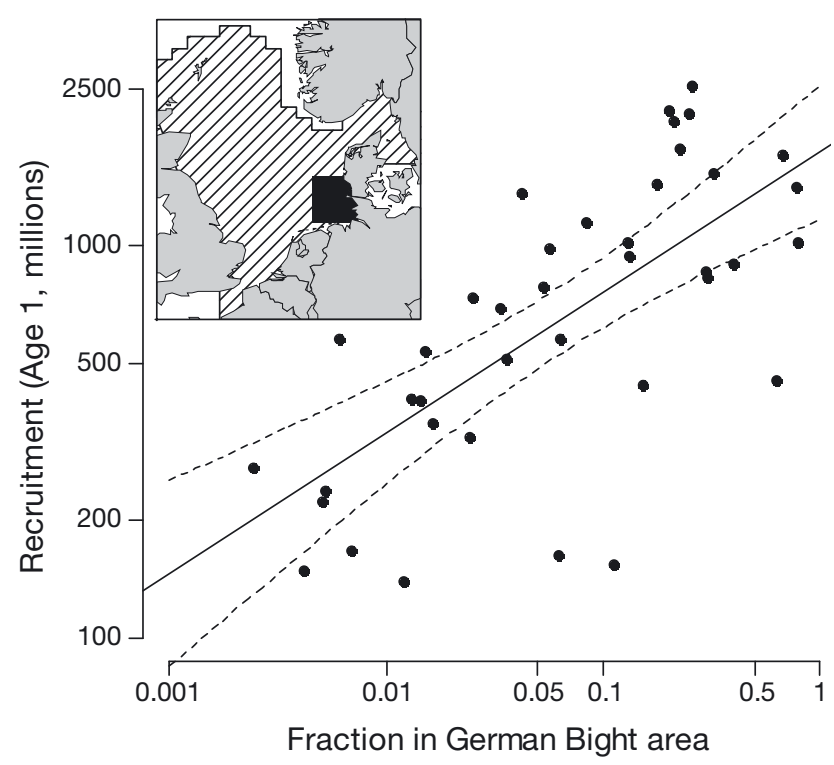

Fig. 3. Gadus morhua. Relationship between recruitment of North Sea cod (measured as number of Age $1 \mathrm{cod}$ ) and the fraction of all Age $1 \mathrm{cod}$ found in the German Bight area (east of $6^{\circ} \mathrm{E}$, south of $55^{\circ} 45^{\prime} \mathrm{N}$ ) in the International Bottom Trawl Survey (IBTS). The estimates of Age 1 cod abundance are from a previous cod assessment (ICES 2011C). The lines show the result of linear regression between the log-transformed variables, with a $95 \%$ confidence interval $\left(\mathrm{R}^{2}=0.48, t=5.84\right.$, $\mathrm{p}<0.0001$ ). The inset shows the German Bight area (black rectangle), as well as the entire area covered by the IBTS (hatched area)

in particular in the northern areas (Fig. 2c,d,h). The abundance of Age 1 herring increased in the southeast but decreased in the northwest (Fig. 2i). The SST has increased basically everywhere (Fig. 2e,j)

The optimal model for cod recruitment varied spatially (Fig. 4; Fig. S3a,c,e in Supplement 2 at www.intres.com/articles/suppl/m480p263_supp.pdf). Cod recruitment was positively associated with the local cod spawning stock abundance in only parts of the area, and with total cod spawning stock abundance in the German Bight and north of Scotland (Fig. 4a,b; see also Fig. S4a,b in Supplement 2). Cod recruitment was negatively associated with local SST in the entire southern NS and with the local abundance of young herring in large parts of the southeastern NS (Fig. 4a,b). When removing long-term trends (i.e. examining only short-term trends), the significant association with temperature persisted in the southernmost areas, while the association with herring abundance remained significant in only a limited part of the area (Fig. 4c). However, when examining the model estimates of the full model (before model selection), it was clear that a tendency still existed for negative effects of both herring and temperature in the German Bight area, but for a large part, they were not statistically significant (Fig. S5c in Supplement 2).

The optimal model for herring recruitment was also highly variable spatially (Fig. 5; Fig. S3b,d,f). Herring recruitment was positively related to local spawner abundance in a few areas of the NS (Fig. 5a; see also Fig. S6a in Supplement 2, but was associated with total spawner biomass in most of the southern NS (Fig. 5b). Local SST had a negative effect on recruitment in the western NS and a non-linearly positive effect in some areas on the southern shores (Fig. 5a,b; Fig. S6a,b). The association between herring recruitment and cod abundance was positive in the central NS and negative in some areas, including the German Bight (Fig. 5b). In contrast to the analysis of cod recruitment, each factor's effect on herring recruitment had roughly the same spatial pattern when long-term trends were removed, although temperature drops out of the model in some areas (Fig. 5c; Fig. S7c in Supplement 2).

\section{DISCUSSION}

Our study adds important spatial dimensions and nuances to both the generally accepted hypotheses of declining NS cod Gadus morhua recruitment (decreased spawning stock and higher temperatures; Cook et al. 1997, Beaugrand et al. 2003) and to the newly proposed mechanism of ecosystem hysteresis through predation by herring Clupea harengus (Fauchald 2010). Regarding the latter hypothesis, we indeed found that the decrease in cod recruitment in a smaller area, the German Bight, was consistent with the hypothesis of strong effects of reciprocal predation between cod and herring. Although this area is small, it has in many years contained a large proportion, or even most, of the cod recruits (Daan et al. 1990). Moreover, we found that high recruitment in this area appears to be related to good cod recruitment in the entire NS, indicating that this is a key nursery area for cod. Our results indicate that the decrease in cod recruitment in this area is not the result of 1 factor alone, but of 3 simultaneous ones: decreased biomass of mature cod, increasing temperatures and increasing abundance of herring (Fig. 4). Furthermore, the increase in herring in this area cannot be fully explained by the increasing total biomass of herring spawners; there appears to be an additional effect of the local abundance of cod spawners, who are important predators of herring. 

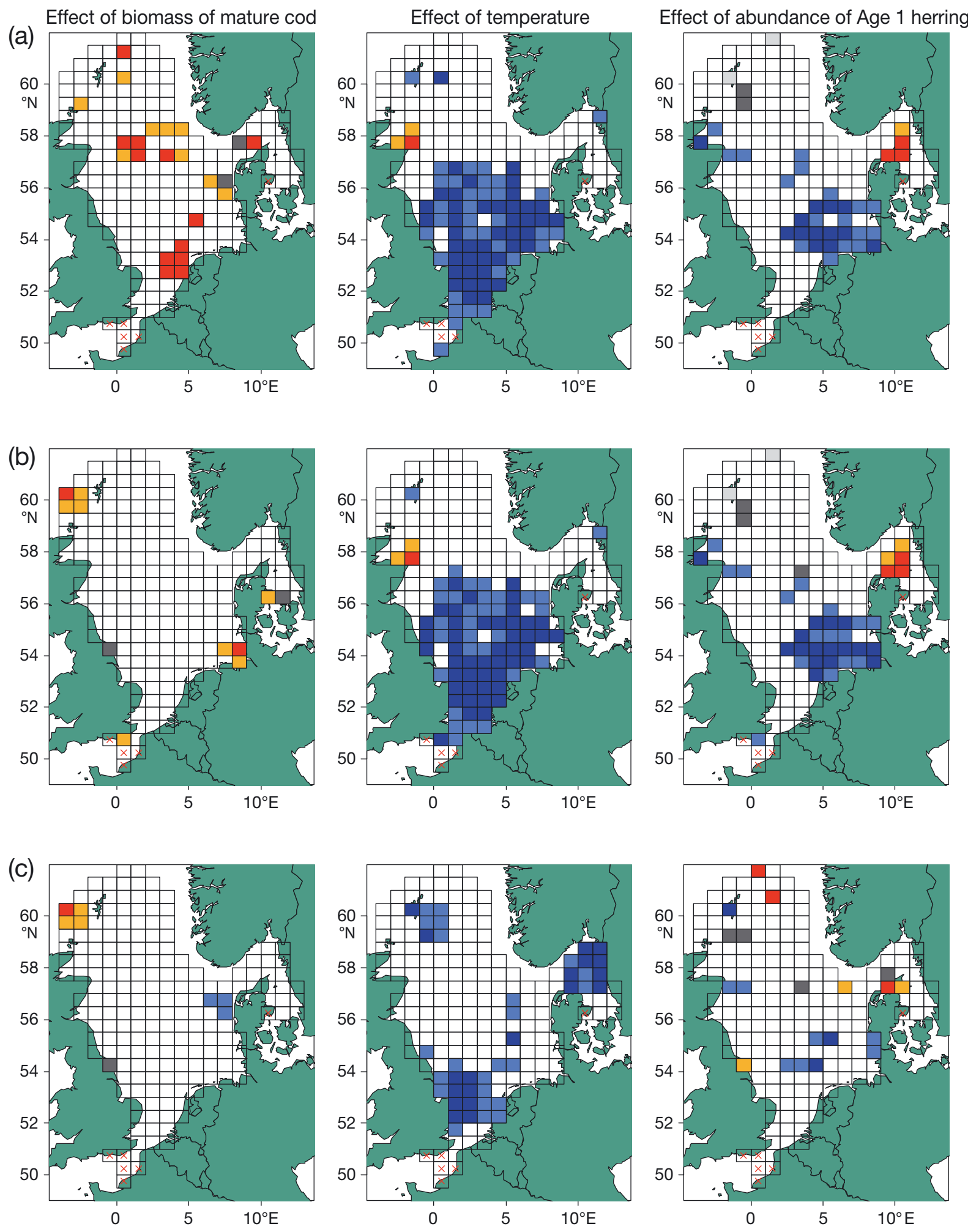

Fig. 4. Gadus morhua. Effect of each predictor variable on cod recruitment. Each row of graphs represents one model: (a) Eq. (1), (b) Eq. (2) and (c) Eq. (3). Dark and light blue indicate predominantly negative effects; dark and light orange indicate predominantly positive effects; and dark and light grey indicate non-effects. Darker shading indicates $p<0.01$, while lighter shading indicates $0.01<\mathrm{p}<0.05$. Red crosses: subareas that were not analysed due to too few years of data. The conditions for classifying effects as 'predominantly negative', 'predominantly positive', or 'non-monotonic' are given in Supplement 3 at www.int-res.com/articles/suppl/m480p263_suppl.pdf; the actual shapes of the effects are given in Supplement 2 (Fig. S4) 

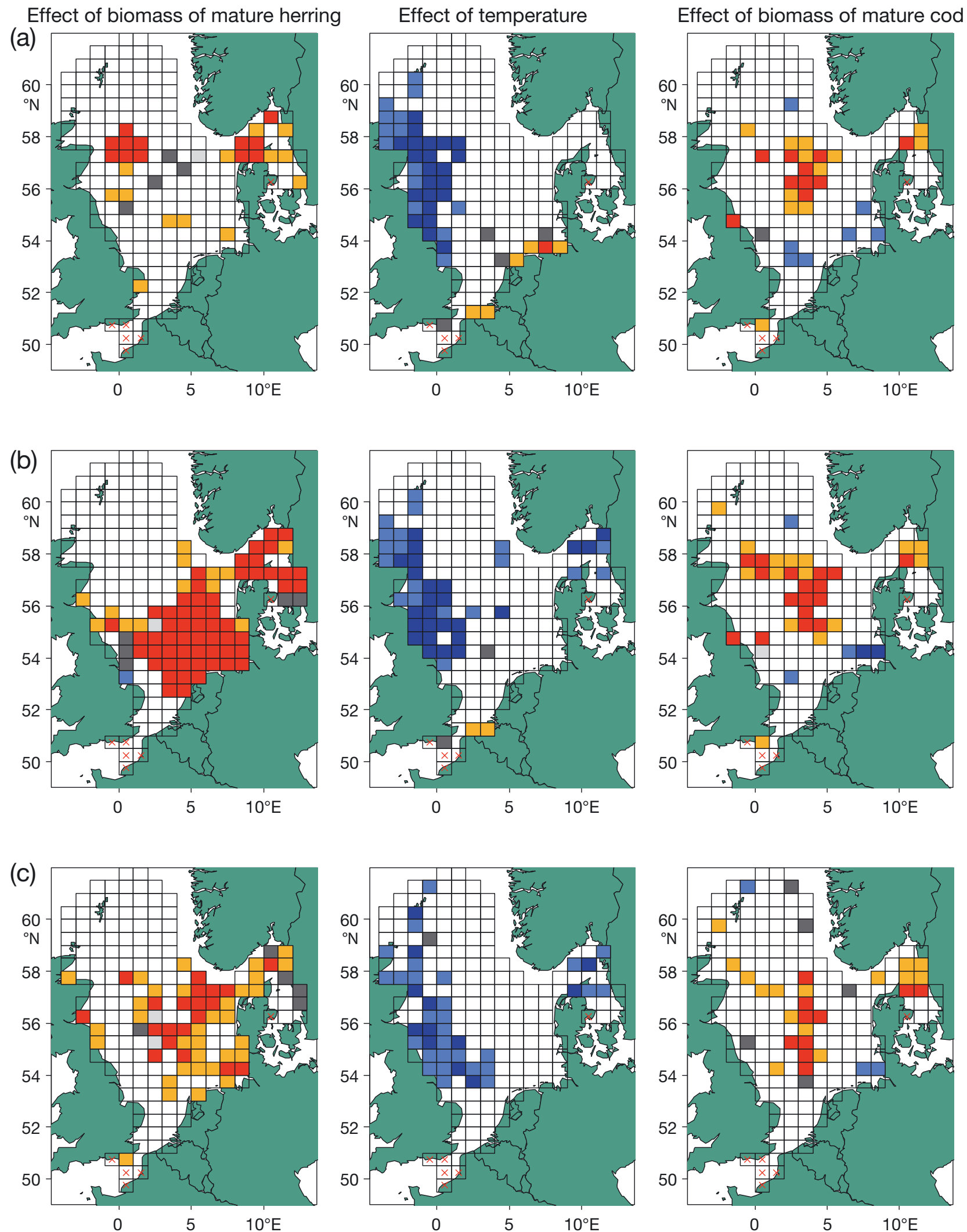

Fig. 5. Clupea harengus. Effect of each predictor variable on the abundance of young herring. Each row of graphs represents one model: (a) Eq. (4), (b) Eq. (5) and (c) Eq. (6). Colours and symbols as in Fig. 4. The actual shapes of the effects are given in Supplement 2 (Fig. S6) 
Our analysis, however, does not explicitly take into account the migrations of adult fish or the drift of eggs and larvae. To investigate the sensitivity of the results to this limitation, we assumed either that spawners contribute only to recruitment in their own subarea, or that they contribute to recruitment anywhere in the NS. These 2 alternative assumptions are extreme end-points: Both cod and herring have eggs and larvae that drift passively with the currents for some time, and, in both cases, the spawning grounds are separate from nursery areas. However, the young are not spread by random all over the NS (e.g. Heath et al. 2008, Gröger et al. 2010).

Both NS cod and NS herring have been found to have substantial spatial structure. In the case of cod, it spawns in several locations in the NS, mostly in the western and southern parts, and the present consensus is that NS cod is likely to be 'composed of a complex of more or less isolated sub-stocks' (ICES 2011c). Based on microsatellite DNA markers, Hutchinson et al. (2001) found 4 genetically distinct groups. Advection patterns indicate that cod in the southern NS (the German Bight, the Dogger Bank and the Southern Bight) are quite isolated from cod in the remaining NS (Heath et al. 2008). Also, the elemental signature of the otoliths indicates that most adults originate from local nursery areas, and that there does not appear to be detectable exchange between spawning areas $>200 \mathrm{~km}$ apart (Wright et al. 2006). Thus, Wright et al. (2006) argued that the NS cod forms a metapopulation, and we would expect cod recruitment to depend on the abundance of spawners in an upstream area. In the case of NS herring, it has 3 or 4 spawning components in separate locations on the west side of the NS; spawning starts in the north in August and ends in January in the south (Daan et al. 1990, Gröger et al. 2010). The herring juveniles of several stocks mix (Ruzzante et al. 2006, Gröger et al. 2010), and as they grow, they gradually move into deeper water; by Age 1 they are spread over the entire southern NS. Thus, for herring, it seems that the most correct assumption is that spawners contribute to recruitment anywhere in the NS (i.e. Fig. 5b). However, herring are more geographically structured than previously believed, as Ruzzante et al. (2006) found clear and temporally stable genetic and morphologic differences between fish from 3 areas (NS, Skagerrak and Kattegat/western Baltic), in spite of the mixing of these 3 stocks in the nursery, feeding and overwintering aggregations. In the cases of both cod and herring, we found the effects of temperature and interspecific predation to be robust to the choice of assumptions.
The relationship between cod and herring has been the subject of much discussion (Cushing 1980, Hislop 1996). It is striking that the papers that suggest a substantial effect of herring predation on cod are based on modelling or statistical analyses (Andersen \& Ursin 1977, Fauchald 2010, Speirs et al. 2010, Minto \& Worm 2012, present paper). In contrast, earlier work based on herring stomach samples (Daan et al. 1985, Last 1989) concluded that herring predates on an insignificant amount of cod eggs. However, recent analyses have revealed that predation on eggs and larvae may be highly localized in space and time (Segers et al. 2007, Temming et al. 2007, Pliru et al. 2012), and stomach samples collected during single seasons may simply miss these important bouts. For the Barents Sea, time-series studies indicating that capelin are heavily affected by herring predation (Hamre 1994, Gjøsæter \& Bogstad 1998, Hjermann et al. 2004) were published several years before field studies were actually able to confirm substantial predation (Hallfredsson \& Pederson 2009). NS herring, being an effective zooplankton feeder, may also be a significant competitor with larval and juvenile cod for food (Cushing 1980, Hislop 1996). For the Norwegian Sea, the most recent studies estimate that herring consumes as much as 50 million tonnes of zooplankton annually and can reduce other species' consumption of the key zooplankton Calanus finmarchicus by $>50 \%$ (Utne et al. 2012). Our analysis suggests that predation and/or competition from herring maytogether with high temperatures-explain some of the decline in NS cod, namely the recruitment failure of the southernmost component of NS cod. Hislop (1996) also pointed to spatial patterns when he argued that the mid-1960s 'gadoid outburst' of cod, whiting and haddock could not have been caused by the reduction of herring: namely, the 1950s to 1960s decline of herring occurred first in the southern NS and later in the northern NS, but the recruitment of the northern-spawning haddock did not increase earlier than that of cod or whiting, which spawn in the south NS as well. Also, Huse et al. (2008) have suggested a similar effect of herring on Norway pout in the NS; they found that the stock-recruitment relationship for this species improved substantially when one considered only the part of the Norway pout SSB not overlapping with herring.

The importance of quantifying predator-prey spatial overlap is increasingly being recognized in analyses of recruitment variation and in the development of recruitment models in the NS. For example, using IBTS data at smaller spatial scales, Temming et al. (2007) illustrated that dense local aggregations of 
juvenile cod could be eliminated by predation, while Kempf et al. (2009) considered the roles of other predators, spatial overlap and temperature to interact in constraining cod recruitment. In a management context, the roles of spatial overlap are increasingly being considered in the development of multispecies NS assessment models (e.g. Kempf et al. 2010), although our analyses extend beyond the species-specific to include life stage/size-specific interactions involving both adults and early life stages.

The consequences and implications of the life stage-specific interactions that we have quantified between species extend beyond the NS. In the Northwest Atlantic, consistent with the hypothesis of role reversals, the cod recruitment rate was inversely related to pelagic fish biomass in the southern Gulf of St. Lawrence (Swain \& Sinclair 2000). On the eastern Scotian Shelf, the combined recruitment of several large-bodied benthic fishes increased only after the biomass of small pelagic fishes declined, suggesting a predator-prey reversal and an explanation for the lagged recovery of benthic fishes following almost 2 decades of fishing moratoria (Frank et al. 2011). Swain \& Mohn (2012) reported that for cod alone, recruitment rate (annual recruitment divided by Age 5+ biomass) was unrelated to forage fish biomass on the eastern Scotian Shelf. However, a meaningful determination of recruitment rates is critically dependent on knowing the annual reproductive potential of the parent stock, which cannot be properly evaluated when significant changes in age and size at maturity, sex ratio, condition factors, or the potential for skipped spawning seasons have occurred (Rideout et al. 2006, Mohn \& Rowe 2012) and been ignored (Marshall et al. 2006, Marshall 2009). Complex interactions between life stages, however, are not unique to pelagic fish preying upon the pelagic early life stages of benthic fishes, as the opposite interactions between benthic and pelagic fishes have also recently been documented, with implications for population management. In the Northwest Atlantic, the dominant benthic fish, haddock Melanogrammus aeglefinus, has been implicated in the decline of Atlantic herring recruitment, due to its overlapping with, and preying upon, benthic herring eggs (Richardson et al. 2011). These complex interactions in other areas serve to highlight the need to consider spatial and stage-specific interactions, and the consequences of pelagic $\times$ benthic interactions influencing population dynamics via more than a single life stage.

Several studies have indicated that temperature has a negative effect on NS cod through lower larval survival due to changes in the plankton community (Beaugrand 2003). This is supported by our study, which also clearly indicates that these negative effects are limited to the southern NS. It has also been suggested that temperatures in the NS are currently so high that they could have a direct negative effect on adult cod via physiological mechanisms (Drinkwater 2005, Pörtner \& Knust 2007). However, Righton et al. (2010) found that southern NS cod do not avoid high temperatures and they have the highest growth rates of all studied stocks, despite experiencing temperatures that have been shown to be very stressful in laboratory experiments. However, during the spawning season (when the survey used in our study was conducted), they found a much narrower temperature range for cod, with a preferred temperature of 5 to $10^{\circ} \mathrm{C}$ across widely separated cod stocks.

When we detrended the data, i.e. removed longterm changes, much of the effects became weaker and were no longer statistically significant. This would be expected if a variable not included in the analysis, and which has a strong trend, was the actual cause of recruitment change. However, it is hard to think of any such effects that are unrelated to the included variables (e.g. fishing effort would mainly decrease recruitment by decreasing SSB). The weakening of the effects can also expected as a purely statistical effect, as much of the variability in the data is removed, decreasing the statistical power of the analysis. Thus, the statistical power might not be sufficient to detect the signal through the noise. A high level of noise (i.e. high variability on small spatial and temporal scales) is unavoidable in analyses of survey data, due to the inherent patchiness of marine fish populations.

It should be noted that the survey method, bottom trawling in winter, is designed to catch young herring as well as demersal fish like cod. Therefore, the method considerably underestimates adult herring, which live more pelagically. However, the abundance patterns seen in the survey are quite consistent with the assessment estimates (Fig. S8b in Supplement 2), which is not surprising, as the catchability in this survey was also used in the assessment of cod and herring biomass (so-called tuning). This suggests that our analyses and interpretations are not biased by the quality of the survey data.

Finally, we note that predation/competition may interact with temperature and spawning stock size. We chose to assume additive effects of the 3 predictor variables, as allowing for interactions would result in too many spurious effects. One may argue that our finding that recruitment is driven by different factors 
in different locations may be a result of this assumption. Thus, the reason that variable $x$ has a significant effect in one place but not in another, may not be the locations per se, but because the range of variable $x$ differs between the sites, or because it interacts with another variable $y$. For instance, Kempf et al. (2009) found that mean SST during the second quarter had a negative effect on recruitment up to a level of $9^{\circ} \mathrm{C}$ but not above this threshold. This result, however, appears to conflict with the fact that cod in the NS already live near the warmest edge of their distributional range in the eastern Atlantic, so we would expect rather the opposite, i.e. that the negative effects of temperature would be aggravated at high temperatures (Drinkwater 2005). This expectation is, however, not supported by the results of Ottersen et al. (2013); while they substantiated that NS cod are affected by temperature, they found no significant changes in recruitment dynamics over the period from 1963 to 2007.

In conclusion, this study quantified spatial variance in the leading mechanisms proposed to affect the variations in important ecosystem components such as cod and herring. Our results support the interpretation that recruitment is affected by a combination of spawning stock abundance and sea temperatures (as suggested by, e.g. Durant et al. 2005, Kempf et al. 2009, Olsen et al. 2011). However, a large, temperate area like the NS can hardly be viewed as a single ecosystem; rather it is a collection of ecosystems the heterogeneous climatic conditions, habitats and species compositions of which differ quite strongly, although their borders are diffuse and unstable and migration among them may be high. While taking this into account obviously makes studies of ecosystem processes more difficult, changes in the spatial structure of marine populations is important, as they can affect the resilience and recovery potential of populations (Ciannelli et al. 2013). The present results support the view that a good understanding of NS cod dynamics is impossible if spatial variability is not taken into account. Although there is no field evidence of substantial predation on cod eggs in the NS, our findings are consistent with the hypothesis that herring have a negative impact on cod recruitment in the German Bight, an area formerly known as a key area for cod recruits (Daan et al. 1990), either through egg predation or competition. However, the direction of causal relationships is inherently difficult to confirm based on time-series data only, despite our efforts to quantify levels of uncertainty and compare multiple models. The existence of hysteresis, or other mechanisms leading to Allee effects in exploited fish, has impor- tant implications for management. Thus, it is important to continue developing and refining methods that are able to take into account spatial variability in a parsimonious manner and to incorporate spatially variable ecosystem processes into management models (Kempf et al. 2010).

Acknowledgements. We thank the Research Council of Norway (RCN) for funding the workshop Tropharct through the MICO project (No. 186310, Match/Mismatch and Ecosystem). This work is associated with the IMBER regional program, Ecosystem Studies of Sub-Arctic Seas (ESSAS). D.O.H. was funded by the RCN (No. 200497, ADMAR). The SST data were provided by the Data Support Section of the Computational and Information Systems Laboratory at the National Center for Atmospheric Research. NCAR is financed by grants from the National Science Foundation. We are grateful to Per Fauchald, Marcos Llope and 3 anonymous reviewers for commenting on an earlier version of the paper.

\section{LITERATURE CITED}

Andersen KP, Ursin E (1977) A multi species extension to the Beverton and Holt theory of fishing with accounts of phosphorus circulation and primary production. Medd Kom Dan Fisk Havunders Fisk 7:319-436

Bartsch J, Brander K, Heath M, Munk P, Richardson K, Svendsen E (1989) Modeling the advection of herring larvae in the North Sea. Nature 340:632-636

Beaugrand G (2003) Long-term changes in copepod abundance and diversity in the north-east Atlantic in relation to fluctuations in the hydroclimatic environment. Fish Oceanogr 12:270-283

Beaugrand G, Brander KM, Lindley JA, Souissi S, Reid PC (2003) Plankton effect on cod recruitment in the North Sea. Nature 426:661-664

Beisner BE, Haydon DT, Cuddington K (2003) Alternative stable states in ecology. Front Ecol Environ 1:376-382

Brander KM (2005) Cod recruitment is strongly affected by climate when stock biomass is low. ICES J Mar Sci 62: 339-343

Ciannelli L, Fisher JAD, Skern-Mauritzen M, Hunsicker ME, Hidalgo M, Frank KT, Bailey KM (2013) Theory, consequences and evidence of eroding population spatial structure in harvested marine fishes: a review. Mar Ecol Prog Ser 480:227-243

Cook RM, Sinclair A, Stefansson G (1997) Potential collapse of North Sea cod stocks. Nature 385:521-522

Courchamp F, Berec L, Gascoigne J (2008) Allee effects in ecology and conservation. Oxford University Press, Oxford

Cushing DH (1980) The decline of the herring stocks and the gadoid outburst. J Cons Int Explor Mer 39:70-81

Daan N, Rijnsdorp AD, Vanoverbeeke GR (1985) Predation by North Sea herring Clupea harengus on eggs of plaice Pleuronectes platessa and cod Gadus morhua. Trans Am Fish Soc 114:499-506

Daan N, Bromley PJ, Hislop JRG, Nielsen NA (1990) Ecology of North Sea fish. Neth J Sea Res 26:343-386

de Roos AM, Persson L, Thieme HR (2003) Emergent Allee effects in top predators feeding on structured prey populations. Proc Biol Sci 270:611-618 
Drinkwater K (2005) The response of Atlantic cod (Gadus morhua) to future climate change. ICES J Mar Sci 62: 1327-1337

Durant JM, Hjermann DO, Anker-Nilssen T, Beaugrand G, Mysterud A, Pettorelli N, Stenseth NC (2005) Timing and abundance as key mechanisms affecting trophic interactions in variable environments. Ecol Lett 8:952-958

Fauchald P (2010) Predator-prey reversal: a possible mechanism for ecosystem hysteresis in the North Sea? Ecology 91:2191-2197

Frank KT, Petrie B, Choi JS, Leggett WC (2005) Trophic cascades in a formerly cod-dominated ecosystem. Science 308:1621-1623

Frank KT, Petrie B, Fisher JAD, Leggett WC (2011) Transient dynamics of an altered large marine ecosystem. Nature 477:86-89

Gjøsæter H, Bogstad B (1998) Effects of the presence of herring (Clupea harengus) on the stock-recruitment relationship of Barents Sea capelin (Mallotus villosus). Fish Res 38:57-71

Gröger JP, Kruse GH, Rohlf N (2010) Slave to the rhythm: how large-scale climate cycles trigger herring (Clupea harengus) regeneration in the North Sea. ICES J Mar Sci 67:454-465

Hallfredsson EH, Pedersen T (2009) Effects of predation from juvenile herring (Clupea harengus) on mortality rates of capelin (Mallotus villosus) larvae. Can J Fish Aquat Sci 66:1693-1706

Hamre J (1994) Biodiversity and exploitation of the main fish stocks in the Norwegian Sea-Barents Sea ecosystem. Biodivers Conserv 3:473-492

Heath MR, Kunzlik PA, Gallego A, Holmes S, Wright PJ (2008) A model of meta-population dynamics for North Sea and West of Scotland cod-the dynamic consequences of natal fidelity. Fish Res 93:92-116

Hislop JRG (1996) Changes in North Sea gadoid stocks. ICES J Mar Sci 53:1146-1156

Hjermann DØ, Stenseth NC, Ottersen G (2004) Indirect climatic forcing of the Barents Sea capelin: a cohort effect. Mar Ecol Prog Ser 273:229-238

Horwood J, O'Brien C, Darby C (2006) North sea cod recovery? ICES J Mar Sci 63:961-968

Huse G, Salthaug A, Skogen MD (2008) Indications of a negative impact of herring on recruitment of Norway pout. ICES J Mar Sci 65:906-911

Hutchinson WF, Carvalho GR, Rogers SI (2001) Marked genetic structuring in localised spawning populations of cod Gadus morhua in the North Sea and adjoining waters, as revealed by microsatellites. Mar Ecol Prog Ser 223:251-260

ICES (International Council for the Explorations of the Sea) (2010) Manual for the international bottom trawl surveys, Revision VIII. Addendum to report of the International Bottom Trawl Survey Working Group. ICES CM 2010/ SSGESST:06

ICES (International Council for the Explorations of the Sea) (2011a) Report of the Working Group on the Assessment of demersal stocks in the North Sea and Skagerrak (WGNSSK). ICES CM 2011/ACOM:13

ICES (International Council for the Explorations of the Sea) (2011b) Report of the Herring Assessment Working Group for the area south of $62^{\circ} \mathrm{N}$ (HAWG). ICES CM 2011/ACOM:06

ICES (International Council for the Explorations of the Sea) (2011c) Report of the ICES Advisory Committee 2011.
ICES Advice, 2011, Book 6. ICES, Copenhagen

Kempf A, Floeter J, Temming A (2009) Recruitment of North Sea cod (Gadus morhua) and Norway pout (Trisopterus esmarkii) between 1992 and 2006: the interplay between climate influence and predation. Can J Fish Aquat Sci 66:633-648

Kempf A, Dingsor GE, Huse G, Vinther M, Floeter J, Temming A (2010) The importance of predator-prey overlap: predicting North Sea cod recovery with a multispecies assessment model. ICES J Mar Sci 67:1989-1997

Kirby RR, Beaugrand G, Lindley JA (2009) Synergistic effects of climate and fishing in a marine ecosystem. Ecosystems 12:548-561

Köster FW, Möllmann C (2000) Trophodynamic control by clupeid predators on recruitment success in Baltic cod? ICES J Mar Sci 57:310-323

Last JM (1989) The food of herring, Clupea harengus, in the North Sea, 1983-1986. J Fish Biol 34:489-501

Llope M, Daskalov GM, Rouyer TA, Mihneva V, Chan KS, Grishin AN, Stenseth NC (2011) Overfishing of top predators eroded the resilience of the Black Sea system regardless of the climate and anthropogenic conditions. Glob Change Biol 17:1251-1265

Marshall CT (2009) Implementing information on stock reproductive potential in fisheries management: the motivation, challenges and opportunities. In: Jakobsen $\mathrm{T}$, Fogarty MJ, Megrey BA, Moksness E (eds) Fish reproductive biology: implications for assessment and management. Blackwell Publishing, Chichester, p 395-420

Marshall CT, Needle CL, Thorsen A, Kjesbu OS, Yaragina NA (2006) Systematic bias in estimates of reproductive potential of Atlantic cod (Gadus morhua) stock: implications for stock-recruit theory and management. Can J Fish Aquat Sci 63:980-994

May RM (1977) Thresholds and breakpoints in ecosystems with a multiplicity of stable states. Nature 269:471-477

Minto C, Worm B (2012) Interactions between small pelagic fish and young cod across the North Atlantic. Ecology 93:2139-2154

Mohn RK, Rowe S (2012) Recovery potential assessment for the Laurentian south designatable unit of Atlantic cod (Gadus morhua): the eastern Scotian Shelf cod stock (NAFO Div. 4VsW). DFO Can Sci Advis Sec Res Doc 2011/138. Department of Fisheries and Oceans, Ottawa

Möllmann C, Mueller-Karulis B, Kornilovs G, St John MA (2008) Effects of climate and overfishing on zooplankton dynamics and ecosystem structure: regime shifts, trophic cascade, and feedback coops in a simple ecosystem. ICES J Mar Sci 65:302-310

NOAA (National Oceanic and Atmospheric Administration) (2011) ICOADS 1 degree. Available at: www.esrl.noaa. gov/psd/data/gridded/data.coads.1deg.html (accessed 1 May 2011)

Olsen EM, Ottersen G, Llope M, Chan KS, Beaugrand G, Stenseth NC (2011) Spawning stock and recruitment in North Sea cod shaped by food and climate. Proc Biol Sci 278:504-510

Ottersen G, Stige LC, Durant JM, Chan KS, Rouyer TA, Drinkwater KF, Stenseth NC (2013) Temporal shifts in recruitment dynamics of North Atlantic fish stocks: effects of spawning stock and temperature. Mar Ecol Prog Ser 480:205-225

Planque B, Frédou T (1999) Temperature and the recruitment of Atlantic cod (Gadus morhua). Can J Fish Aquat Sci 56:2069-2077 
Pliru A, van der Kooij J, Engelhard GH, Fox CJ, Milligan SP, Hunter E (2012) Sprat feeding behaviour, selective predation, and impact on plaice egg mortality. ICES J Mar Sci 69:1019-1029

Pörtner HO, Knust R (2007) Climate change affects marine fishes through the oxygen limitation of thermal tolerance. Science 315:95-97

Richardson DE, Hare JA, Fogarty MJ, Link JS (2011) Role of egg predation by haddock in the decline of an Atlantic herring population. Proc Natl Acad Sci USA 108: 13606-13611

Rideout RM, Morgan MJ, Lilly GR (2006) Variation in the frequency of skipped spawning in Atlantic cod (Gadus morhua) off Newfoundland and Labrador. ICES J Mar Sci 63:1101-1110

Righton DA, Andersen KH, Neat F, Thorsteinsson V and others (2010) Thermal niche of Atlantic cod Gadus morhua: limits, tolerance and optima. Mar Ecol Prog Ser 420:1-13

Ruzzante DE, Mariani S, Bekkevold D, Andre C and others (2006) Biocomplexity in a highly migratory pelagic marine fish, Atlantic herring. Proc Biol Sci 273:1459-1464

Scheffer M, Carpenter S, Foley JA, Folke C, Walker B (2001) Catastrophic shifts in ecosystems. Nature 413:591-596

Segers FHID, Dickey-Collas M, Rijnsdorp AD (2007) Prey selection by North Sea herring (Clupea harengus), with special reference to fish eggs. ICES J Mar Sci 64:60-68

Submitted: June 13, 2012; Accepted: February 26, 2013
Speirs DC, Guirey EJ, Gurney WSC, Heath MR (2010) A length-structured partial ecosystem model for cod in the North Sea. Fish Res 106:474-494

Swain DP, Mohn RK (2012) Forage fish and the factors governing recovery of Atlantic cod (Gadus morhua) on the eastern Scotian Shelf. Can J Fish Aquat Sci 69:997-1001

Swain DP, Sinclair AF (2000) Pelagic fishes and the cod recruitment dilemma in the Northwest Atlantic. Can J Fish Aquat Sci 57:1321-1325

Temming A, Floeter J, Ehrich S (2007) Predation hot spots: large scale impact of local aggregations. Ecosystems 10:865-876

Utne KV, Hjøllo SS, Huse G, Sogen M (2012) Estimating the consumption of Calanus finmarchicus by planktivorous fish in the Norwegian Sea using a fully coupled 3D model system. Mar Biol Res 8:527-547

Walters C, Kitchell JF (2001) Cultivation/depensation effects on juvenile survival and recruitment: implications for the theory of fishing. Can J Fish Aquat Sci 58:39-50

Wood SN (2011) Fast stable restricted maximum likelihood and marginal likelihood estimation of semiparametric generalized linear models. J R Stat Soc, B 73:3-36

Wright PJ, Neat FC, Gibb FM, Gibb IM, Thordarson H (2006) Evidence for metapopulation structuring in cod from the west of Scotland and North Sea. J Fish Biol 69(Suppl C):181-199

Proofs received from author(s): April 3, 2013 